\title{
Confecom, 10 anos depois: um debate necessário sobre a implementação das propostas aprovadas
}

Confecom, 10 years later: a necessary debate on the implementation of the approved proposals

Confecom, 10 años después: un debate necesario sobre la implementación de las propuestas aprobadas

Octavio PENNA PIERANTI, Brasil

octavio.pieranti@gmail.com

Chasqui. Revista Latinoamericana de Comunicación

N. ${ }^{\circ} 141$, agosto - noviembre 2019 (Sección Ensayo, pp. 275-288)

ISSN 1390-1079 / e-ISSN 1390-924X

Ecuador: CIESPAL

Recibido: 03-02-2019/Aprobado: 16-11-2019 


\section{Resumo}

Uma década depois da realização da I Conferência Nacional de Comunicação (Confecom) no Brasil, é recorrente a análise de que as propostas aprovadas não foram implementadas. Este artigo tem o objetivo de avaliar se essa análise é procedente. Para isso foram examinadas as 633 propostas aprovadas, sendo separadas as programáticas ou impossíveis de serem mensuradas. Verificou-se que pouco mais de um terço das restantes foram implementadas, no todo ou em parte. O grande símbolo da conferência, um novo marco regulatório para o setor, não foi elaborado e enviado ao Congresso Nacional.

Palabras clave: Confecom; comunicações; conferência; políticas públicas

\section{Abstract}

A decade after the first National Communication Conference (Confecom) in Brazil, it is commonly said that the approved proposals were not implemented. This article aims to assess whether this analysis is appropriate. The 633 approved proposals were examined and the proposals that were programmatic or impossible to be measured were excluded from the sample. It was found that more than a third of the rest were implemented, in whole or in part. The great symbol of the conference, a new regulatory framework for the sector, was not prepared and submitted to the National Congress.

Keywords: Confecom; communications; conference; public policies

\section{Resumen}

Una década después de la primera Conferencia Nacional de Comunicación (Confecom) en Brasil, se dice comúnmente que las propuestas aprobadas no se implementaron. Este artículo pretende evaluar si este análisis es apropiado. Fueron examinadas las 633 propuestas aprobadas y se excluyeron de la amuestra las propuestas programáticas o imposibles de medir. Se encontró que más de un tercio del resto se implementó, en su totalidad o en parte. El gran símbolo de la conferencia, un nuevo marco regulatorio para el sector, no fue preparado y presentado al Congreso Nacional.

Palavras-chave: Confecom; comunicaciones; conferencia; políticas públicas 


\section{Introdução}

No dia 17 de dezembro de 2009, depois de quatro dias de debates, terminou a $1^{a}$ Conferência Nacional de Comunicação (Confecom) realizada no Brasil. O caderno com 633 propostas aprovadas, editado no ano seguinte (Ministério das Comunicações, 2010), é resultado de um trabalho que envolveu cerca de 1.800 delegados da sociedade civil, do empresariado e de governos nas três esferas; 15 grupos de trabalho (GT); 27 etapas estaduais e distrital; e dezenas - talvez centenas - de etapas municipais, conferências livres e debates relacionados ao tema desde abril daquele ano, mas nunca mapeados na íntegra.

Essa trajetória não foi simples. A realização da conferência, durante todo o ano de 2009, esteve sempre ameaçada. Para que todo o esforço resultasse na plenária final de dezembro, em Brasília-DF, foi necessário conviver com a saída de grande parte dos empresários da Comissão Organizadora Nacional (CON). A permanência das outras duas entidades desse segmento foi garantida com uma metodologia de trabalho atípica para conferências. Envolvia, em síntese, divisão das vagas de delegados segundo cotas fixas (40\% para a sociedade civil; $40 \%$ para o empresariado; $20 \%$ para os governos), regras específicas para questões consideradas sensíveis por um dos segmentos, pouca deliberação nas etapas estaduais e nenhuma nas municipais e a necessidade de busca de consensos mínimos para seguir adiante seja na aprovação das propostas, seja na condução dos trabalhos da própria CON.

Este artigo, contudo, não almeja recontar essa história, mas parte desse contexto para atingir seu objetivo. Passada uma década da realização da Confecom, este artigo tem por objetivo avaliar a implementação das propostas aprovadas. Vale lembrar que a conferência não foi "vinculativa", ou seja, não foi estabelecido compromisso político e legal de adoção de todas as propostas pelo governo federal, Congresso Nacional e outros atores responsáveis. No entanto, seria razoável supor que a dedicação de tantas pessoas e horas de trabalho, em um ambiente de discussão democrático, resultasse em medidas concretas.

\section{A literatura acadêmica sobre as propostas da Confecom}

Antes de tratar especificamente da implementação das propostas, faz-se necessário abordar o contexto em que elas foram construídas, bem como as expectativasgeradas.Em2009, àmedida em que osmeses passavam, os problemas aumentavam e a CON era instada a tomar decisões difíceis, conformando uma conferência que seria guiada segundo metodologia incomum, resumida anteriormente. Nesse período, também crescia a mobilização em torno do tema. A participação nas etapas estaduais era concorrida. Segmentos da sociedade civil organizavam suas pautas, a serem apresentadas em formato de propostas à 
conferência. Isso foi feito, por exemplo, por sindicatos, movimento de mulheres, rádios comunitárias e entidades representativas de diversos grupos (Mattos, 2013; Peruzzo, 2010; Veloso \& Rebouças, 2011). Representantes das empresas e dos governos também apresentaram suas propostas e as defenderam nas etapas estaduais. Guias e roteiros para uma atuação mais eficiente dos delegados na conferência foram publicados; dentre esses, pelo menos um livro, que ainda está disponível na internet (Melo, Iraci \& Vieira, 2009).

As propostas aprovadas chegaram a ser analisadas como uma tentativa de "aperfeiçoar, numa direção liberal-democrata, o sistema brasileiro de comunicações" (Dantas, 2010, p. 15). Além disso, pode-se dizer que a etapa nacional coroava o terceiro momento de sucesso (ainda que com diversos conflitos), desde a década de 1980, em que o Poder Público, empresários e sociedade civil dispunham-se a construir alternativas, por meio de um diálogo estruturado, para questões específicas sobre as comunicações. O primeiro ocorreu durante a Assembleia Nacional Constituinte e o segundo, durante o processo de aprovação da Lei do Cabo de 1995 (Pieranti, 2011), resultando em documentos bem mais sintéticos que o relatório final da Confecom. A singularidade do momento mereceu reconhecimento:

Em meio a distorções, ela também construiu avanços. Provocou o debate, colocou à mesa de negociação segmentos antagônicos, revelou aos setores conservadores que há uma força civil articulada e experiente em praticar o exercício coletivo do poder. Enfim, a CONFECOM foi um passo adiante na luta para democratizar a Comunicação. O processo não se encerra na realização da mesma, pois, a efetivação de suas propostas vai depender de ações do Poder Executivo da promulgação de leis pelo Congresso Nacional. Portanto, o embate seguirá difícil. (Peruzzo, 2010, p. 15)

E, de fato, seguiu difícil. Grande parte das propostas aprovadas dependia de alteração na legislação vigente e o governo federal constituiu, em 2010, um grupo de trabalho com o objetivo de propor uma minuta de novo "marco regulatório" das comunicações, além de ter organizado um seminário internacional sobre o tema. Essa expressão rapidamente se tornaria uma bandeira de quem pretendia avançar nos debates da Confecom. A minuta foi entregue à nova gestão que se iniciava em 2011 no plano federal. O ambiente institucional e a conjuntura de forças complexos, contudo, começavam a preocupar:

A Confecom chegou ao fim, então, com um amplo documento que evidencia as demandas de toda a sociedade no campo da comunicação e dialoga com as tendências regulatórias internacionais dos países democráticos. Sua implementação depende, no entanto, de um pacto entre diferentes segmentos da sociedade, capaz de promover a revisão do marco legal e de outros instrumentos normativos. Depende, ainda, da percepção da necessidade de atuação do Estado não no sentido de controle da comunicação, mas, sim, de regulação da mesma 
segundo perspectiva de garantia de direitos fundamentais e de prestação de alguns serviços em contextos muito específicos. Depende, por fim, da consagração da participação da sociedade civil organizada no que se refere à formulação, à implementação e à avaliação das políticas públicas no campo da comunicação. (Pieranti, 2011, p. 260-1)

Alguns pesquisadores começaram a levantar dúvidas sobre a implementação das propostas ainda em 2011. Criticava-se, por exemplo, a falta de um compromisso público sobre prazos e propostas de ações, dentre as quais a apresentação de um projeto de lei pelo governo federal: "as declarações confusas do novo ministro, aliadas às poucas informações oficiais disponibilizadas contribui para a constatação de que existe uma tendência de dissipação do debate" (Barros, 2011, p. 16).

Além das críticas à condução do tema pelo governo, discutia-se se as próprias propostas aprovadas na Confecom, de alguma forma, contribuíam para a falta de medidas concretas. Chegava-se a apontar o excesso de propostas, várias das quais parecidas, como possível entrave (Pelegrini \& Schiavo, 2014; Sousa \& Barbalho, 2014). Também se disse que as propostas voltadas a alguns temas, como TV digital e convergência de mídias, tendiam a ser generalistas, tendo sido rejeitadas as alternativas mais incisivas (Zambon \& Carvalho, 2010). Ou, então, que ideias similares e polêmicas eram até aprovadas como moções, mas seus autores não conseguiam aprovar uma proposta que as reunisse (Xavier, 2013).

Com o passar dos anos, foram promulgadas, no Brasil, novas leis que tratavam de temas específicos do campo das comunicações. Assim foram aprovadas, por exemplo, a lei $\mathrm{n}^{\circ} \mathbf{1 2 . 4 8 5}$, de 12 de setembro de 2011, para tratar do Serviço de Acesso Condicionado (TV por Assinatura); a lei $n^{\circ} 12.965$, de 23 de abril de 2014, o Marco Civil da Internet; e a lei no 13.709 , de 14 de agosto de 2018, sobre a proteção de dados pessoais. Segmentos da sociedade civil chegaram a elaborar e discutir um projeto de lei de iniciativa popular, que veio a ser intitulado "Lei da Mídia Democrática”, sem, contudo, reunir o apoio necessário para apresenta-lo e aprova-lo no Congresso Nacional. E o Ministério das Comunicações propôs revisões pontuais de leis e decretos, além de ter regulamentado e revisto normas aplicáveis a diferentes serviços, como radiodifusão educativa, comunitária e retransmissão de TV.

O "marco regulatório", entendido como uma lei geral para o setor das comunicações, contudo, não foi apresentado. No governo federal, chegou a ser referenciado, ainda como um debate em construção, em 2010. Depois, em 2011 e 2012, voltou a ser citado publicamente. Em 2014, a regulação econômica das comunicações chegou a ser abordada na campanha eleitoral para Presidente da República. E, em 2015, o Ministério das Comunicações voltou a ensaiar o debate, porém a crise política que resultou no impeachment, no ano seguinte, impediu sua continuidade (Pieranti, 2017). 
Análises mais recentes sobre a implementação das propostas aprovadas na Confecom têm confluído para o entendimento de que quase nenhuma delas gerou consequências concretas em termos de novas políticas públicas (Valente, 2014; Demarchi, 2017; Demarchi; Kerbauy, 2018). De 2011 a janeiro de 2019, época em que se concluiu este artigo, o governo federal não publicou relatórios ou estudos que confrontassem essa visão ou que, pelo menos, relacionassem as ações por ele implementadas como fruto das propostas da Confecom. Também não foram encontrados, na literatura acadêmica, estudos que tenham se proposto a analisar todas as propostas com o objetivo de avaliar sua implementação.

É possível dizer que o governo federal e o Congresso Nacional (atores a quem se destinavam grande parte das propostas da Confecom) ignoraram, na década seguinte, os debates realizados? Acredito que essa constatação só é possível a partir de uma análise - ainda que sucinta, em função da limitação de espaço das conclusões dos delegados que se dedicaram a debater as comunicações, em Brasília, há cerca de uma década.

\section{Classificação das propostas}

A análise deste artigo parte de uma categorização das propostas aprovadas, que constam do relatório final da conferência (Ministério das Comunicações, 2010). As 633 propostas foram separadas em 4 grupos. Sempre que for feita referência a alguma delas em específico, seu número no relatório será apresentado entre parênteses.

O primeiro grupo reúne 163 propostas consideradas programáticas ou não passíveis de mensuração. Convém citar exemplos. Entre as programáticas estão "a produção regional deve atender a requisitos de qualidade, profissionalismo, ética e respeito à diversidade cultural regional e direitos humanos, sob pena de ser enquadrada em lei específica" (575) e "controlar o cumprimento das regras pertinentes às da radiodifusão comunitária, exigindo de quem tem outorga a observância deste compromisso" (267). Entre as que não podem ser medidas está "garantia do cumprimento da política de classificação indicativa em todas as regiões do país" (159): como uma grande parte dos conteúdos está sujeita às regras de classificação indicativa, é impossível saber se essas estão sendo respeitadas em todos os locais, a todo tempo.

Excluídas essas 163 propostas, restam outras 470 propostas, ou seja, cerca de 74,25\% do total. A análise sobre a implementação, desenvolvida nas próximas páginas, considerará apenas essas 470 propostas, já que a avaliação das demais resta prejudicada pelo critério adotado e já exposto. Elas foram divididas em três grupos: não implementadas (grupo 2), parcialmente implementadas (3) e totalmente implementadas (4) e serão tratadas na próxima seção.

O reconhecimento de cada proposta em uma dessas categorias passa por um julgamento que carrega certa dose de subjetividade. Entende-se, porém, que não havia como ser diferente, visto que, em nenhum momento nesses últimos 
dez anos, o governo federal e o Congresso Nacional (a quem se destinava grande parte das propostas) avaliaram publicamente a implementação das propostas. Ou seja, não há documentos oficiais nos quais se basear. Além disso, algumas propostas aprovadas reuniam, na verdade, duas ou mais propostas (semi-) autônomas ou aplicáveis a um conjunto diverso de segmentos da população. Ainda assim, foram consideradas como uma só proposta, preservando-se a estrutura original do relatório final. Se essas propostas foram implementadas para apenas parte dos segmentos, foram incluídas no grupo 3 .

A análise aqui realizada é, portanto, uma, mas certamente não a única, forma de avaliar a implementação das propostas aprovadas na Confecom. Seria possível prever outras categorias, por exemplo. Observada essa característica, acredita-se que esta análise contribui para uma reflexão sobre os desdobramentos da conferência.

\section{Análise da implementação das propostas}

As 470 propostas remanescentes foram divididas nas categorias "não implementadas" (2), "parcialmente implementadas" (3) e "totalmente implementadas" (4), conforme tabela a seguir:

Tabela 1: Análise da implementação das propostas aprovadas (geral)

\begin{tabular}{|c|c|c|}
\hline Categoria & $\mathbf{N}^{\circ}$ de propostas & $\%$ \\
\hline 2 & 309 & 65,74 \\
\hline 3 & 121 & 25,74 \\
\hline 4 & 40 & 8,52 \\
\hline Total & 470 & 100 \\
\hline
\end{tabular}

Fonte: Elaboração do autor

Faz-seimportante citar alguns exemplos de propostas em cada categoria. Entre as não implementadas está "lutar pela ampliação dos mecanismos de gestão da EBC e demais emissoras públicas, garantindo maior participação social nos conselhos $e$ autonomia da sociedade na indicação de seus membros" (41). Não apenas o modelo de conselhos não foi expandido, de forma institucional e regular, para (quase) todas as outras emissoras educativas vinculadas a governos estaduais e outras que pudessem ser caracterizadas como públicas, como também o Conselho Curador da EBC foi extinto por medida provisória, convertida na lei $\mathrm{n}^{\circ}$ 13.417, de $1^{\circ}$ de março de 2017. Também consta dessa categoria a proposta "criar um programa de editais que contemple a aquisição de equipamentos para as TVs do campo público, assim como a redução de impostos de importação sobre equipamentos de audiovisual e áudio, não fabricados no Brasil, para fomentar a produção independente(...)" (532), porque nunca foi criado um programa com essa finalidade.

A proposta "apoiar a implantação dos canais do poder executivo, da cultura, da educação e da cidadania, previstos com a criação do Sistema Brasileiro de 
Televisão Digital" (506) pode ser citada como uma parcialmente implementada. Os canais da Cultura, da Educação e da Cidadania foram regulamentados, projetos de gestão foram formulados pelos órgãos responsáveis e canais mantidos pelo Poder Executivo (NBr, TV Escola e Canal Saúde) começaram a ser transmitidos, nas maiores capitais do país, pela TV aberta, fruto do uso do recurso da multiprogramação em parceria com a TV Brasil. No entanto, parte dos canais mencionados na proposta não chegou a ser implementada e o modelo de veiculação dos já existentes não foi expandido para outras cidades. Outra proposta parcialmente implementada foi "que sejam fomentadas as produções nacionais e regionais de conteúdos, soluções e aplicações, assegurando pluralidade de informação e de opiniões" (585). Houve, na última década, um aumento consistente de ações de fomento a produções nacionais e regionais, desenvolvidas pela Ancine, Ministério da Cultura, EBC e diversos órgãos e entidades não apenas federais (Ancine, 2017), como será mencionado a seguir. No entanto, não houve uma regra comum a todas essas iniciativas que objetivasse a garantia do pluralismo, como, por exemplo, um valor máximo de recursos públicos que poderiam ser obtidos por uma mesma empresa. Daí a consideração de que essa proposta não foi implementada na íntegra.

A proposta "manter o processo de governança da Internet no Brasil como modelo multissetorial e democrático, garantindo assim a participação da sociedade" (470) é exemplo de uma que foi implementada, não tendo ocorrido, desde então, mudança significativa no modelo de governança cujo principal símbolo é o CGI.br. Também foi totalmente atendida a proposta "que sejam abertos editais para habilitação para novas rádios comunitárias” (835), com a publicação de Planos Nacionais de Outorgas (PNOs) que contemplaram, por exemplo, de 2011 a 2013, um terço dos municípios brasileiros com a possibilidade de novas outorgas (Pieranti, 2017).

As propostas que foram implementadas, no todo ou em parte, somam, portanto, pouco mais de um terço $(34,25 \%)$ dentre todas as passíveis de serem mensuradas. É quase natural considerar esse percentual como baixo. No entanto, essa afirmação dependeria da referência a ser empregada. Em outras palavras, para sustenta-la com o rigor acadêmico necessário, seria importante comparar esse percentual com o verificado, por exemplo, em relação a propostas de conferências inéditas como a Confecom e realizadas na mesma época. Essa comparação não foi feita neste estudo, o que impede a afirmação. No entanto, é possível concluir, a partir de estudos publicados e debates havidos desde então, que esse percentual é bem inferior ao esperado por grande parte dos envolvidos. Ninguém comemorou, desde a conclusão da Confecom, um alto índice de propostas implementadas.

Os debates na Confecom foram estruturados segundo GTs temáticos. Um olhar sobre aqueles cujas propostas mais foram implementadas pode sinalizar áreas em que houve mais mudanças concretas na última década: 
Tabela 2: GTs com mais propostas implementadas

\begin{tabular}{|c|l|c|c|}
\hline GT & \multicolumn{1}{|c|}{ Temas } & Cat.(3+4) & $\%$ \\
\hline 1 & Produção independente; produção regional; e garantia de distribuição & 27 & 54 \\
\hline 8 & $\begin{array}{l}\text { Sistema de outorgas; fiscalização; propriedade das entidades distribuidoras de } \\
\text { conteúdo }\end{array}$ & 14 & 53,85 \\
\hline 6 & Internet; telecomunicações; banda larga; infraestrutura & 19 & 51,35 \\
\hline
\end{tabular}

Fonte: Elaboração do autor

O GT 1 responde pela maior proporção de propostas implementadas, no todo ou em parte, dentre todos os da Confecom. Um elemento importante nesse âmbito é o Fundo Setorial do Audiovisual, criando antes da conferência, em 2006, pela lei $n^{\circ}$ 11.437. Depois da Confecom, a lei $n^{\circ} 12.485 / 11$ ajudou a reestruturar a política de fomento ao audiovisual brasileiro, ao atrair novos canais estrangeiros, gerar espaço para a produção nacional por meio de cotas e ampliar o número de agentes responsáveis por contribuir com o FSA. Assim, ao mesmo tempo em que se gerou mercado para a produção nacional, cresceram os recursos destinados ao fomento: apenas os valores disponibilizados por esse fundo aumentaram de $\mathrm{R} \$ 37$ milhões, em 2009, para mais de $\mathrm{R} \$ 755$ milhões em 2016 (Ancine, 2017). E a essa fonte se somaram várias outras, provenientes de órgãos e entidades públicas nos três níveis de governo.

Também em relação aos temas do GT 8 houve mudanças significativas na última década, o que explica o alto índice de propostas implementadas no todo ou em parte. Foram promulgadas mudanças pontuais na legislação, mas, neste caso específico, elas não foram tão centrais à alteração de foco das políticas públicas. Por meio da revisão de suas portarias e dinâmicas internas, o ministério, de 2011 a 2016, passou a prever regras mais objetivas e claras para processos de outorgas dos diferentes serviços; instituiu PNOs, com calendários públicos, para contemplar um grande número de municípios com novas emissoras e disponibilizou, em seu site, dados sobre controladores das entidades detentoras de outorgas e outras informações (Pieranti, 2017). É verdade que, findo esse período, diminuíram os dados publicados no site sobre as entidades detentoras de outorgas e os PNOs foram interrompidos ou substituídos por outros menores. Ainda assim, o cenário de janeiro de 2019 - quando foi concluído este artigo - é melhor que o existente na época da Confecom.

O GT 6 completa o rol daqueles com maior percentual de propostas aprovadas. Nesse caso, foram determinantes a promulgação do Marco Civil da Internet e da Lei Geral de Proteção de Dados Pessoais. Além disso, não houve retrocessos no modelo de governança da Internet no Brasil, defendido por grande parte da sociedade civil em 2009. Nos anos seguintes à conferência, o governo federal começou a promover, de forma mais direta, ações voltadas à expansão da banda larga, demanda flagrante da Confecom. Entre essas iniciativas estiveram o lançamento do Plano Nacional de Banda Larga (PNBL) e suas posteriores alterações e a reativação da Telebrás, em uma tentativa de 
subsidiar com recursos públicos, de alguma forma, os valores envolvidos na expansão.

Deve-se, agora, analisar os GTs quegeraram menos propostasimplementadas, em termos proporcionais, na década seguinte. Essa informação consta da tabela a seguir.

Tabela 3: GTs com menos propostas implementadas

\begin{tabular}{|l|l|l|l|}
\hline GT & Temas & Cat. (3+4) & $\%$ \\
\hline 15 & $\begin{array}{l}\text { Respeito e promoção das diversidades cultural, religiosa, étnico-racial, de } \\
\text { gênero, orientação sexual; proteção a segmentos vulneráveis, como crianças e } \\
\text { adolescentes }\end{array}$ & 9 & 16,07 \\
\hline 13 & $\begin{array}{l}\text { Classificação indicativa; órgãos reguladores; aspectos federativos; marco legal e } \\
\text { regulatório }\end{array}$ & 4 & 17,39 \\
\hline 5 & Rádio; rádios e TVs comunitárias & 5 & 21,74 \\
\hline
\end{tabular}

Fonte: Elaboração do autor

O GT 15 tem duas peculiaridades. Foi o grupo com menor proporção de propostas implementadas nesta última década. Além disso, é o que teve o maior número de propostas aprovadas, todas por consenso. Dessas, 62 foram enquadradas na categoria 1, ou seja, eram programáticas ou não mensuráveis. As outras 56 analisadas geraram o resultado exposto. Algumas das propostas, no todo ou em parte, dependeriam da promulgação de leis específicas, como, por exemplo, garantir um recorte racial na aplicação de recursos do Fundo de Universalização das Telecomunicações (Fust), que, na verdade, foram muito pouco utilizados como um todo (776), ou obrigar a contratação de um percentual específico de negros pelas empresas de comunicação (452). No entanto, a maior parte das propostas dependia simplesmente da implementação de políticas públicas que não foram colocadas em prática. Esse era o caso, por exemplo, da proposição voltada ao fomento da produção audiovisual de mulheres com objetivo de desconstrução de estereótipos de gênero (763), o que poderia ter sido objeto de editais específicos. Também era o caso do pleito para a constituição de núcleos jurídicos que assistissem à população negra e afro-religiosa em casos de violação dos seus direitos pelos meios de comunicação (495). Note-se que essas propostas, assim como várias outras, poderiam ter sido implementadas por outros órgãos que não aqueles mais diretamente relacionados ao tema das comunicações (ministérios das Comunicações e da Cultura, agências reguladoras a eles vinculadas, Secretaria de Comunicação Social da Presidência da República e órgãos que os sucederam).

OGT13, o segundo com menos propostasimplementadas, tevena classificação indicativa um de seus principais temas de debate. À época da Confecom, a regulamentação desse tema parecia consolidada. Em 2016, no mesmo dia em que o Senado Federal julgou o impeachment da presidenta da República, Dilma Rousseff, o Supremo Tribunal Federal declarou inconstitucional a aplicação de sanções a emissoras que violavam a classificação indicativa. Essa 
era uma ferramenta central para lidar com a questão. Além disso, o GT aprovou propostas, dentre outras, que diziam respeito à formação de comissões para as próximas conferências (174), criação de conselhos em emissoras públicas e universitárias (178 e 189, por exemplo), alterações na estrutura regulatória do setor no país (195) e a regulamentação de dispositivos constitucionais (279). A implementação das propostas, na maioria dos casos, ensejaria a aprovação de um novo marco regulatório para as comunicações. A não promulgação dessa nova lei explica o baixo índice de propostas aprovadas neste grupo.

O terceiro GT com menos propostas implementadas versou sobre temas ligados à comunicação comunitária. Em que pesem iniciativas empreendidas na última década, como a publicação de PNOs para rádios comunitárias e a regulamentação do Canal da Cidadania na TV Digital, grande parte das propostas aprovadas no GT dependeria de alteração legal. É exemplar, nesse caso, a situação da radiodifusão comunitária. A lei $n^{\circ} 9.612$, de 19 de fevereiro de 1998, que regulamenta esse serviço, estabelece medidas restritivas que não se aplicam a nenhum outro serviço de radiodifusão. Podem ser citadas, por exemplo, as previsões de potência máxima, altura do sistema irradiante, atribuição de apenas um canal para a prestação desse serviço em cada localidade e permissão de veiculação apenas de mensagens de apoio cultural (que não se confundem com publicidade comercial). O GT 5 aprovou propostas tentando alterar esse panorama (735 e 822, por exemplo), assim como pleiteou a criação de um fundo para apoiar as emissoras (719) e a descriminalização de operações sem outorga (788). Essas medidas demandariam a promulgação de nova lei, o que não ocorreu. Outras iniciativas aprovadas, como o apoio técnico do ministério das Comunicações a comunidades que quisessem instalar uma emissora (802), também não foram adiante. Também houve propostas sobre as quais se caracterizou perda de objeto, já que baseadas em alguma outra política pública inconclusa. Como exemplo, cite-se a defesa de que o modelo de rádio digital deveria contemplar tecnologia nacional (817). Até janeiro de 20190 governo federal não havia decidido sequer que o rádio digital seria adotado no Brasil, nem sinalizava a tomada de qualquer posição nesse sentido.

\section{Conclusão}

Este artigo teve o objetivo de avaliar a implementação das propostas aprovadas na I Conferência Nacional de Comunicação, realizada em dezembro de 2009. Para atingi-lo, foi necessário revisitar cada uma das 633 medidas deliberadas, dividindo-as entre as que são programáticas ou não mensuráveis; as não implementadas; as parcialmente implementadas e as totalmente implementadas. As integrantes do primeiro grupo foram excluídas da análise. Verificou-se que $34,25 \%$ das demais - ou seja, pouco mais de um terço - foram implementadas, em parte ou no todo. 
Várias propostas foram citadas a título de exemplo nesse artigo. É pública a relação de todas elas, sendo possível encontrar o relatório final da Confecom em diversos sites, dentre os quais o mencionado na seção de referências que subsidiaram este artigo. As propostas citadas como exemplo demonstram, de pronto, a preocupação dos delegados eleitos para a conferência com uma ampla gama de temas, para os quais sugeriram iniciativas bastante concretas. Acredita-se que o alto número de propostas deve ser encarado como fruto do consenso possível em um processo de "catarse coletiva" do qual participaram atores que pouco dialogaram e muito brigaram desde que a Constituição Federal de 1988 foi promulgada. A simples construção coletiva da Confecom, por isso mesmo, pode ser considerada uma vitória. $\mathrm{O}$ amplo rol de propostas, se não era o ideal sob a perspectiva de formulação de políticas públicas, tampouco deve ser usado como justificativa para inviabilizá-las.

Entende-se que a metodologia adotada neste artigo não permite afirmar se foram "poucas" ou "muitas" as propostas implementadas. Para fazer esse juízo de valor, seria necessário buscar referências para a comparação. As mais evidentes seriam outras conferências, seus relatórios finais e as propostas implementadas, analisadas segundo as mesmas categorias aqui adotadas. Essa comparação, contudo, não foi feita, mas pode ensejar pesquisas futuras.

De toda sorte, é possível afirmar que mais propostas poderiam ter sido implementadas. Várias delas - e exemplos foram mencionados ao longo deste artigo - não dependiam sequer de novas leis. Poderiam ter sido fruto de portarias dos próprios órgãos ou de políticas públicas. Eventualmente sequer demandariam recursos públicos. Seja porque não foram priorizadas pelos diferentes governos, seja porque a máquina pública não tenha conseguido reunir os esforços suficientes para implementá-las, contudo, elas restaram, por enquanto, apenas como registros no relatório final da conferência. Em vários casos, ainda são atuais e, quem sabe, ainda poderão ser implementadas.

Mudanças estruturais no campo das comunicações, defendidas pelos delegados presentes à Confecom, demandariam uma nova legislação. A expressão "marco regulatório" tornou-se o maior símbolo da conferência e passou a ser usada em diversos debates ao longo dos anos que se seguiram. No entanto, um novo marco regulatório, com a amplitude que dele se esperava na conferência, chegou apenas a ser elaborado em 2010 (no formato de minuta para discussão interna no governo) e referenciado, em alguma medida, nos anos seguintes. Na década seguinte à conferência, não foi encaminhado ao Congresso Nacional. Essa ausência talvez ajude a explicar uma percepção muitas vezes manifestada, inclusive em trabalhos citados neste artigo, de que as propostas da conferência não foram implementadas.

Outro destino, porém, tiveram algumas iniciativas legislativas, também debatidas na Confecom e, por vezes, esquecidas como frutos da conferência ou, pelo menos, como iniciativas que receberam seu apoio. Esse é o caso da Lei do Serviço de Acesso Condicionado (TV por Assinatura), do Marco Civil da Internet 
e da Lei Geral de Proteção de Dados Pessoais, sendo o debate, nesse último caso, bem mais embrionário na conferência. As propostas aprovadas também inspiraram decretos e portarias, dentre os quais diversos regulamentos de serviços de radiodifusão. Assim, a despeito de um marco regulatório amplo não ter sido sequer encaminhado ao Congresso Nacional, é importante registrar que governos e, claro, o próprio Parlamento se engajaram, com sucesso, na aprovação de alterações legais que ajudaram a construir o atual cenário das comunicações no país.

Também é preciso registrar o que pode ser considerada uma falha de comunicação de diferentes governos. Não foram feitas avaliações periódicas e públicas sobre a implementação das propostas da Confecom. Quando elas foram postas em prática, as autoridades responsáveis não lembraram publicamente que elas haviam nascido ou, pelo menos, sido aprovadas na conferência. Nesse sentido, faltou a percepção de que uma conferência não termina em sua plenária final; ainda que não oficialmente instalada, ela aguarda a implementação de suas deliberações e é razoável que seja informada sobre o que foi feito a respeito do relatório final.

Por fim, a realização de uma segunda Confecom chegou a ser ventilada apenas de forma esparsa nessa última década. Talvez a defesa mais consistente nesse sentido tenha ocorrido durante as eleições presidenciais de 2018. Ainda assim, pelos debates realizados, pelo nível das propostas apresentadas, pelo engajamento em torno do tema e pela capacidade de articular atores tão heterogêneos, entendo que esse modelo de conferência contribuiu e voltaria a contribuir para a construção de políticas públicas democráticas e plurais no campo das comunicações.

\section{Referências bibliográficas}

Ancine. (2017). Uma nova política para o audiovisual: Agência Nacional do Cinema, os primeiros 15 anos. Rio de Janeiro: Ancine. Recuperado de https://www.ancine.gov.br/sites/ default/files/livros/ANCINE\%2015\%20ANOS\%20WEB\%2OFINAL_em\%2obaixa2.pdf

Barros, C. T. G. (2011). Radiodifusão brasileira e marco regulatório: Confecom e propostas. Estudos em Jornalismo e Mídia, 8 (1). Recuperado de https://periodicos.ufsc.br/index. php/jornalismo/article/download/1984-6924.2010v8n1p6/18937

Dantas, M. (2010). Resultados da $1^{\text {a }}$ Confecom: uma avaliação preliminar. XVIII Encontro da Compós. Recuperado de http://compos.com.puc-rio.br/media/g6_marcos_dantas.pdf

Demarchi, C. H. (2017). Perspectivas para a democratização da comunicação no Brasil após a Confecom: breves apontamentos. Jornada Científica de Comunicação Social. Recuperado de https://www.usc.br/custom/2008/uploads/anais/comunic_social_2017/Temas_livres/ Carlos_Henrique_Demarchi_perspectivas_para_a_democratizacao.pdf

Demarchi, C. H., \& Kerbauy, M. T. M. (2018). A democratização da mídia no Brasil pós-Confecom (2010). [2017]. proposta de um estudo de caso. Revista Mídia e Cotidiano, 12 (1). Recuperado de http://periodicos.uff.br/midiaecotidiano/article/download/9863/6993 
Mattos, S. (2013). A Revolução digital e os desafios da comunicação. Cruz das Almas-Bahia: Editora UFRB. Recuperado de http://www.repositorio.ufrb.edu.br/bitstream/123456789/766/1/a\%2orevolucao\%2odigital\%2Oe\%20os\%2odesafios\%2oda\%2O comunicacao(1).pdf.

Melo, J., Iraci, N., \& Vieira, V. (2009). Fazendo lobby: guia de participação de delegadas/os no processo de negociação e incidência na $1^{a}$ Conferência Nacional de Comunicação (CONFECOM). São Paulo: Rede Mulher de Educação. Recuperado de http://www.bibliotecadigital. abong.org.br/bitstream/handle/11465/776/1563.pdf? sequence=1

Ministério das Comunicações (2010). Caderno $1^{a}$ Confecom: Conferência Nacional de Comunicação. Brasília-DF: Secom-PR. Recuperado de http://pfdc.pgr.mpf.mp.br/atuacao-econteudos-de-apoio/publicacoes/comunicacao/caderno-propostas-1a-confecom

Pelegrini, M., y Schiavo, S. F. (2014). Participação Popular na Mídia é Censura? CECS-Publicações/eBooks. Recuperado de http://revistacomsoc.pt/index.php/cecs_ebooks/article/ download/1710/1645

Peruzzo, C. M. K. (2010). Rádios Comunitárias no Brasil: da desobediência civil e particularidades às propostas aprovadas na CONFECOM. Encontro Anual da Compós. Disponível em: http://compos.com.puc-rio.br/media/g6_cicilia_peruzzo.pdf

Pieranti, O. P. (2011). O Estado e as Comunicações no Brasil: Construção e Reconstrução da Administração Pública. Brasília, DF: Abras/Lecotec.

_. (2017). Políticas Públicas de Radiodifusão no Governo Dilma. Brasília, DF: Universidade de Brasília, Faculdade de Comunicação.

Sousa, E., \& Barbalho, A. (2014). Entre a derrubada de barreiras e as teses dos conselhos de comunicação na I Confecom: uma análise das posições do empresariado participante. Eptic, 16 (3), 16-31. Recuperado de

https://seer.ufs.br/index.php/eptic/article/viewFile/16/pdf

Valente, J. (2014). 5 anos de Confecom: muito barulho por nada? Carta Capital, 19 dez. Recuperado de http://www.sjpdf.org.br/direitos/40-artigos-de-opiniao/2219-5-anosde-confecom-muito-barulho-por-nada

Veloso, A. M. da C., \& Rebouças, E. (2011). As políticas e estratégias do feminismo brasileiro junto aos meios de comunicação no Brasil em tempos de Conferência Nacional de Comunicação (CONFECOM). Redes.Com, (6), 29-40. Recuperado de https://dialnet.unirioja.es/ descarga/articulo/3919443.pdf

Xavier, T. M. N. (2013). Confecom e o direito de comunicar. Rio de Janeiro: UFRJ (Monografia). Recuperado de https://pantheon.ufrj.br/bitstream/11422/4013/1/TXavier.pdf

Zambon, P., \& Carvalho, J. M. de. (2010). Confecom: processo decisório e ações dos grupos de mídia. III Encontro Ulepicc-Br. 